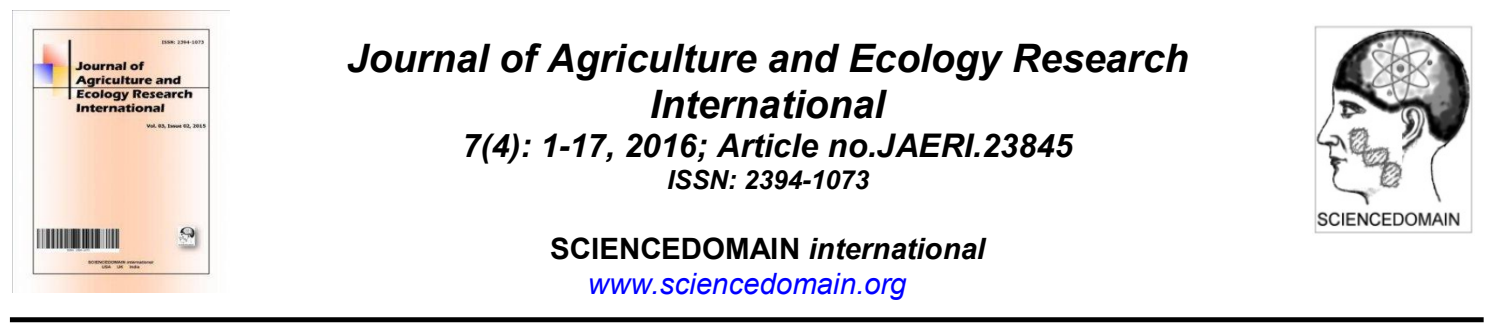

\title{
Synthesis of Nylon-ferrous Oxide Chitosan Immobilised Silica Nanoprobe for Detection of Ralstonia solanacearum
}

\author{
Gatahi Dennis Maina ${ }^{{ }^{*}}$, Wanyika Harrison $\mathrm{Njuma}^{2}$, Kihurani Agnes Wanjiru ${ }^{3}$ \\ and Odingo Dezzline Adhiambo ${ }^{4}$ \\ ${ }^{1}$ Department of Horticulture, Jomo Kenyatta University of Agriculture and Technology, \\ P.O.Box 62000-00200, Nairobi, Kenya. \\ ${ }^{2}$ Department of Chemistry, Jomo Kenyatta University of Agriculture and Technology, \\ P.O.Box 62000-00200, Nairobi, Kenya. \\ ${ }^{3}$ Department of Crop Science, Karatina University, P.O.Box 1957-10101, Karatina, Kenya. \\ ${ }^{4}$ Department of Physical Science, Karatina University, P.O.Box 1957-10101, Karatina, Kenya.
}

\section{Authors' contributions}

This work was carried out in collaboration between all authors. Author WHN designed the study, sourced the materials, supervised the experiments and validated protocols. Author KAW managed all literature searches, supervised the experiments and validated the protocols. Author ODA participated in experiments and protocols development. Author GDM performed the experiments, wrote the protocols and wrote the first draft of the manuscript. All authors read and approved the final manuscript.

Article Information DOI: 10.9734/JAERI/2016/23845 Editor(s):

(1) George Tsiamis, Department of Environmental and Natural Resources Management, University of Patras, Greece. Reviewers:

(1) S. Umesha, University of Mysore, Karnataka, India. (2) Mostafa Helmy Mostafa, Ain Shams University, Cairo, Egypt. Complete Peer review History: http://sciencedomain.org/review-history/14238

Original Research Article

Received $24^{\text {th }}$ December 2015 Accepted $1^{\text {st }}$ February 2016 Published $19^{\text {th }}$ April 2016

\section{ABSTRACT}

Accurate detection of plant pathogen precedes control. Misdiagnosis of diseases results in chemical waste, crop damage and ultimately income loss. Precision in pathogen detection has been made possible by advances in plant pathology, biotechnology and nanotechnology. For instance, PCR and fluorescent kits have been developed to detect diseases. On-farm utilisation of 
the aforementioned technologies has been limited by the expertise required and cost. Colorimetric nanoprobes have been applied in detection of water pathogens and heavy metals. This study entailed development of nylon-ferrous oxide chitosan-silica nanoprobe for Ralstonia solanacearum pathogen. Electrospun nanofibres were used as support for ferrous oxide chitosan immobilised silica nanocomposite (FeOCISNC) gel. The materials were selected due to their compatibility, large surface area for microbial adsorption and high affinity of iron by $R$. solanacearum bacteria. Optimisation experiments were carried out to determine the concentration of components and $\mathrm{pH}$ that yielded highest iron oxide nanoparticles (FeONPs). There was significantly high yield $(P=.05)$ when a ratio of 2:3 (v/v) for green tea extract to iron chloride solution and a $\mathrm{pH}$ of 6 were used. Synthesised composites were characterised using X-ray powder difraction (XRD). The resulting nanomaterials had crystallite sizes of 3.96, 5.00 and $11.60 \mathrm{~nm}$ for FeONPs, FeOCISNC and nylonFeOCISNC respectively. Detection of $R$. solanacearum was marked by colour change from grey to brown in the presence of the isolated pathogen. This was also corroborated by XRD characterisation; the nanoprobe adsorbed pathogen had a crystallite size of $14.75 \mathrm{~nm}$. Additionally, the time required for optimal adsorption of FeOCISNC gel and pathogen suspension on the nylon nanofiber and nylon-FeOCISNC probe respectively was determined using optical density (O.D) of the suspensions after adsorption. There was no significant difference $(P=.05)$ in the O.D of FeOCISNC gel when nylon nanofibres were immersed for $8 \mathrm{hr}, 16$ and $48 \mathrm{hr}$. Also, the O.D of the pathogen suspension was not significantly different $(P=.05)$ after 5,30 and 60 min which validated the observation that the change in colour intensity from grey to brown on the nanoprobe was not visually different within the time period. The colour change was attributed to the disruption of the pathogen membrane by glucosamine units in chitosan followed by complexation, absorption and reduction of iron oxide. Absorption of iron from the nanocomposite was due to the high affinity for iron by the bacteria. It can be concluded that, the combination of ferrous oxide and chitosan silica nanocomposites gel produced a rapid, precise and user friendly tool for detection of the lethal pathogen. The precise detection will consequently form the basis for the pathogen control.

Keywords: Nanopathogenic probe; gel; adsorption; electrospinning; chelation; affinity.

\section{INTRODUCTION}

Horticultural crops are threatened by several diseases. The pathogens develop exponentially due to the favourable high temperature and humidity conditions particularly in greenhouses. In severe infection, up to $100 \%$ crop losses occur [1].

Crop losses can be ameriorated and specific treatments developed to control the pathogens if the diseases are accurately diagnosed and identified prior to spreading. The conventional methods of identifying plant pathogens have been through physical observation which is only possible after damage has been done to the crop. This limits the effectiveness of any remedial strategy. To save plants from irreparable damage by pathogens, farmers have to identify an infection before the disease manifests using a disease diagnostic kit [1,2].

Development of disease diagnostic kits has been made possible by advances in molecular biology, plant pathology, and biotechnology [3]. The kits are designed to detect plant diseases early, either by identifying the presence of the pathogen in the plant or the molecules produced by either the pathogen or the plant during infection $[4,5]$. These techniques are rapid and accurate in detecting pathogens. For instance, PCR kits have been developed to detect black Sigatoka disease in banana [6], Phytophthora infestans in potato and Fusarium in cotton [7]. Also, enzyme-linked immunosorbent assay (ELISA) method has been used in the detection of viruses [8]. However the adoption of these diagnostic kits has been limited by high initial and maintenance costs and farmers' limitation on technical knowhow. Thus the need for development of low cost, farmer friendly and low maintenance pathogen diagnostic kits using nanotechnology $[9,10]$.

Recently, there has been intensified research on the use of nanocolorimetric probes in detecting water pathogens where molecules of biotic and abiotic origin bind selectively to the analyte with concomitant change in color [11]. Although the technology of nanocolorimetric detection is still not fully developed, it is becoming popular due to its simplicity, rapidity and sensitivity [12]. Colorimetric nanoparticles becomes effective when supported by polymers preferably the nanofibres which offer a large surface area that allow exposure to analytes, resulting in increased 
sensitivity. Various polymeric materials have been used, for instance, cellulose and other polysaccharides [13]. However, nylon nanofibres are the most remarkable due to their fascinating properties such as high strength, surface energy, surface reactivity, thermal and electrical conductivity [14]. Nanomaterials exhibit unique mechanical, optical, magnetic and electronic properties as a result of their nanoscale dimensions [12].

\section{EXPERIMENTAL}

\subsection{Materials}

All reagents were of high degree of purity at least analytical grade and were obtained from Sigma Aldrich UK for mesoporous silica nanoparticles $(2 \mathrm{~nm})$, acetic acid, sodium hydroxide pellets, hydrated iron chloride, calcium oxychloride (chlorox), tetrazolium chloride and tripolyphosphate. Chitin 99\% was obtained from Laborex and nutrient agar, $R$. solanacearum, Fusarium solani primers and other molecular reagents from Bioneer Corporation. The electrospun nylon-nanofibres $(200 \mathrm{~nm})$ were obtained from South Africa (Rhodes University, Department of Chemistry). Green tea (POF) was obtained from KTDA-Kangaita Tea Factory Ltd (Kenya) while diseased tomato plants were obtained from a greenhouse infested with $R$. solanacearum in Kiambu County, Kenya.

\subsection{Experimental Site and Design}

The experiments were carried out in Jomo Kenyatta University of Agriculture and Technology at the departments of Horticulture and Chemistry. The experiments were laid on a completely randomized design and replicated three times. The tests were done under sterile conditions in growth chambers and/or lamina flow.

\subsection{Preparation of Green Iron Oxide Nanoparticles (FeONPs)}

Iron oxide nanoparticles were synthesised using green tea extracts; the green tea extract was prepared by heating $60.0 \mathrm{~g} \mathrm{~L}^{-1}$ green tea (KTDA, Kangaita T.F.) until boiling. After settling for 1.0 $\mathrm{hr}$, the extract was vacuum-filtered. Separately, a solution of $0.10 \mathrm{M} \mathrm{FeCl}_{2} \cdot 4 \mathrm{H}_{2} \mathrm{O}$ was prepared by adding $19.9 \mathrm{~g}$ of solid $\mathrm{FeCl}_{2} \cdot 4 \mathrm{H} 2 \mathrm{O}$ (Aldrich Sigma) in $1.0 \mathrm{~L}$ of distilled water. Subsequently optimisation tests were carried out, then $0.10 \mathrm{M}$ $\mathrm{FeCl}_{2} \cdot 4 \mathrm{H}_{2} \mathrm{O}$ solution was added to $60.0 \mathrm{~g} \mathrm{~L}^{-1}$ green tea in $2: 3$ volume ratios. After which $1.0 \mathrm{M}$ $\mathrm{NaOH}$ solution was added until a $\mathrm{pH}$ of 6.0 was attained. Formation of iron oxide nanoparticles was marked by appearance of an intense black precipitate. The precipitate was centrifuged at $3500 \mathrm{rpm}$ for $10 \mathrm{~min}$ then iron oxide particles separated by evaporating water from the iron solution on a hot plate $\left(80^{\circ} \mathrm{C}\right)$ and finally dried for $24 \mathrm{hr}$ in a fume hood [15]. The formed iron oxide nanoparticles were quantified using SHIMADZU Atomic Absorbance spectrophotometer (AAS) and characterised using Rigaku Manniflex II Desktop X-ray defractogram (XRD) machine. Elemental analysis of the nanocomposites was done using the X-ray fluorescence (XRF) technique [16].

\subsection{Synthesis of Ferrous Oxide Chitosan Immobilised Silica Nanocomposites (FeOCISNC)}

Chitosan immobilised silica was synthesised following the sol-gel centrifugation method. The green synthesised iron oxide nanoparticles were added to the CISNC gel in a rotary shaker until colour changed to dark grey. The mixture was stirred for $1 \mathrm{hr}$ to form a homogenous mixture [17].

\subsection{Synthesis of Nylon-FeOCISNC}

Strips of electrospun nylon fibres $(200 \mathrm{~nm})$ were placed in a beaker containing the FeOCISNC gel for $4,8,12,24,48 \mathrm{hr}$ to allow adsorption of the gel on the nylon nanofibres. The nylon nanofibres adsorbed with FeOCISNC were then dried on pretridishes in a sterilised lamina flow at $25^{\circ} \mathrm{C}$ for $24 \mathrm{hr}$ before storage in a refrigerator at $10^{\circ} \mathrm{C}[18]$.

\subsection{Characterisation of Nylon-FeCISNC Using XRD}

The synthesised nylon-ferrous oxide CISNC were characterised using $X$-ray diffraction machine with a radiation of wavelength $1.5418 \mathrm{~A}^{\circ}$ at scan range of $1-120^{\circ}$ at a scanning rate of $1^{\circ} \%$ min with a step size of $0.04^{\circ}$. The obtained difractograms confirmed formation of the nanocomposite [19].

\subsection{Isolation, Identification and Culturing of $R$. solanacearum and $F$. solani}

Diseased hybrid tomato plant material was obtained from a greenhouse in Thika, Kiambu County in an area heavily infested by the disease 
[2]. The plants were thoroughly washed to remove dirt and dipped in $1 \%$ chlorox for sterilisation. The lower stem was cut into small pieces of $5 \mathrm{~cm}$ each then cut longitudinally and placed in a 1 It beaker containing distilled water to allow flow of bacterial exudates. The obtained bacteria were cultured in a sterilised growth chamber for $48 \mathrm{hr}$ at $32^{\circ} \mathrm{C}$ on $20 \mathrm{ml}$ nutrient-TZC agar contained in a petridish. $F$. solani pathogen was also isolated from an infested greenhouse soil and cultured on PDA agar at $25^{\circ} \mathrm{C}$ for $96 \mathrm{hr}$. The colonies observed using a hand lens and Nixon compound microscope [20].

\subsection{Colorimetric Tests of Nylon- FeOCISNC in $R$. solanacearum}

$R$. solanacearum and $F$. solani cultures were standardised to 3.000 O.D at $600 \mathrm{~nm}$ using a SHIMADZU Ultra violet-visible spectrophotometer (Uv-vis) and placed in $50 \mathrm{ml}$ beakers. Nylon-ferrous oxide CISNC probes were placed in the suspensions for 5,30 and $60 \mathrm{~min}$, then placed on a petridish. Control involved placing the nanoprobe in distilled water, while another test involved placing the probe in a $F$. solani suspension. The tests were carried out under sterile conditions in a lamina flow.

\subsection{Elemental Analysis of the Nanocomposites Products Using the $X$-ray Fluorescence (XRF) Technique}

Energy dispersive X-ray fluorescence spectrometer (EDXRF) unit, JSX-3202-M was used for elemental analysis of the nanocomposites products using the X-ray fluorescence (XRF) technique. The sample analysis involved mixing the sample in a mixer to make it homogeneous then placing the sample in the sample holder $[16,21]$.

\subsection{Validation of the Colorimetric Nanoprobe Using PCR and Morphological Techniques}

To obtain DNA from the isolated and morphologically identified microbes, the cells were cultured on TZC treated nutrient agar and PDA for $R$. solanacearum and $F$. solani respectively. The cultured inocula were added to distilled water to form suspensions. The suspensions were standardised to an optical density (O.D) of 3.000 observed at $600 \mathrm{~nm}$ on Uv-vis. DNA was extracted following the CTAB extraction method and then stored at $-20^{\circ} \mathrm{C}$ [6].
The polymerase chain reaction (PCR) was carried out using touchdown procedure. The primers were a 20 mer forward primer -GAA CGC CAA CGG TGC GAA CT-, and reverse GGC GGC CTT CAG GGA GGT C- and Forward primer (5'-ATGGGTAAGGAAGGACAAGAC-3') and the reverse primer (5'GGAGAGTACCAGTGCATCATGTT-3') for virulent $R$. solanacearum and $F$. solani strains respectively. The samples were cooled at $4{ }^{\circ} \mathrm{C}$ and subjected to electrophoresis on a $1.5 \%$ agarose gel in $1 \mathrm{X}$ TAE buffer (40 mM Tris acetate and $1.0 \mathrm{mM}$ EDTA), photographs of the images were taken under ultra-violet (Uv) light. The obtained ladders were interpreted using base pair amplicons for pathogen detection [3].

\subsection{Data Analysis}

Data of iron oxide yield and adsorption of $R$. solanacearum pathogen on the nanoprobe were subjected to analysis of variance (ANOVA), the means were compared by Fischer's Least Significant Difference (LSD 0.05). The X-ray difractograms were interpreted as depicted by the peaks. Linear fits were used to show the trend for adsorption of FeOCISNC gel on the nylon nanofibres and yield of iron oxide at different conditions [19].

\section{RESULTS AND DISCUSSION}

\subsection{Green Iron Oxide Nanoparticles (FeONPs) Synthesis}

The reaction of green tea extract and hydrated iron chloride resulted in formation of iron oxide. Results of obtained are corroborated by linear fit in Fig. 1 and the variation in mean yield per treatment depicted in Table 1.

The linear fit showed a strong correlation between absorbance resulting from yield of iron oxide nanoparticles (FeONPs) and concentration of reagents. Absorbance was also affected by the $\mathrm{pH}$ since sodium hydroxide was added to raise the $\mathrm{pH}$ in order to achieve higher iron oxide yield.

Optimal yield of iron oxide by reduction using green tea extract was attained at a $\mathrm{pH}$ of 6 , when the concentration of iron chloride solution was higher than that of green tea extract (v/v). Low $\mathrm{pH}$ and concentration of iron chloride resulted in less amount of iron oxide yield. Iron nanoparticles rich in iron oxide/oxohydroxide 
were readily prepared using green tea extract. The material possesses different morphology and structural characteristics than iron oxide nanoparticles produced by reduction with sodium borohydride [22,23]. The yield of iron oxide nanoparticles was affected by the concentration of green tea liquor, ratio of green tea to iron chloride used and the resultant $\mathrm{pH}$ of the mixture (Table 1 and Fig. 1). The quantity of iron oxide nanoparticles obtained was directly proportional to $\mathrm{pH}$ and ratio of green tea to iron ions concentration. Optimal iron oxide yield was attained at a $\mathrm{pH}$ of 6 at a ratio of 2:3 for green tea to iron chloride.

The ability of tea extract and hydrated iron chloride to form iron oxide was attributed to the reducing effect of green tea liquor. This is because, tea is very rich in polyphenols which are known for their reducing effect [24]. This process is environmentally safe, unlike other reducing agents such as sodium borohydride which is carried out in a fume chamber due to the toxic fumes emitted. The compound is also highly corrosive and flammable thereby posing a potential hazard during utilisation [15]. Another advantage of using tea extracts in synthesis of the iron oxide nanoparticles is the impartation of steric stabilisation resulting in electrostatic repulsion which hinders aggregation of the nanoparticles [25]. Plant phenolic compounds are attributed to redox reactions when mixed with reactive substances [26]. The redox reactions by the plant polyphenols are attributed to hydrogen donation, oxygen removal and chelation of metals [27].

The outcome was in agreement with Karori et al. [28]; Carmen et al. [29], that tea extracts are strong reducing agents and that the reducing effect decrease when tea is oxidised before drying. Therefore, green tea also known as nonoxidised or non-fermented tea possesses good reducing properties. Koech et al. [30] and Dutta et al. [31] found out that oxidation of tea resulted in a chemical process, with formation of theaflavins and thearubigins a process that is not reversible.

Table 1. Yield of iron oxide nanoparticles (FeONPs)

\begin{tabular}{lll}
\hline Treatment & pH & FeONPs yield (\%) \\
\hline $0.5 \mathrm{M}(2: 3)$ & $\mathrm{pH} 2$ & $10.35 \mathrm{a}$ \\
$0.5 \mathrm{M}(3: 2)$ & $\mathrm{pH} 6$ & $11.74 \mathrm{~b}$ \\
$0.5 \mathrm{M}(2: 3)$ & $\mathrm{pH} 4$ & $12.86 \mathrm{c}$ \\
$1.0 \mathrm{M}(3: 2)$ & $\mathrm{pH} 6$ & $14.05 \mathrm{~d}$ \\
$1.0 \mathrm{M}(2: 3)$ & $\mathrm{pH} 6$ & $14.59 \mathrm{e}$ \\
$0.5 \mathrm{M}(2: 3)$ & $\mathrm{pH} 8$ & $14.69 \mathrm{e}$ \\
$2.0 \mathrm{M}(2: 3)$ & $\mathrm{pH} 2$ & $14.69 \mathrm{e}$ \\
$1 \mathrm{M}(3: 2)$ & $\mathrm{pH} 4$ & $14.79 \mathrm{e}$ \\
$0.5 \mathrm{M}(2: 3)$ & $\mathrm{pH} 6$ & $14.85 \mathrm{e}$ \\
$2.0 \mathrm{M}(2: 3)$ & $\mathrm{pH} 4$ & $15.44 \mathrm{f}$ \\
$1 \mathrm{M}(3: 2)$ & $\mathrm{pH} 8$ & $15.52 \mathrm{f}$ \\
$1.0 \mathrm{M}(2: 3)$ & $\mathrm{pH} 6$ & $15.53 \mathrm{f}$ \\
$2.0 \mathrm{M}(3: 2)$ & $\mathrm{pH} 6$ & $16.29 \mathrm{~g}$ \\
$2 \mathrm{M}(2: 3)$ & $\mathrm{pH} 6$ & $17.64 \mathrm{~h}$ \\
$2 \mathrm{M}(2: 3)$ & $\mathrm{pH} 8$ & $17.68 \mathrm{~h}$ \\
\hline
\end{tabular}

The ratios $(\mathrm{v} / \mathrm{v})$ represents iron oxide to green tea extract

S.E. $\quad$ C.V\%

$0.0497 \quad 0.3$

Means followed by different letters are significantly different at $P=.05$

The $\mathrm{pH}$ of the mixture affects reduction of iron oxide by tea extracts due to concentration of hydrogen ions. Very high hydrogen ions associated with low $\mathrm{pH}$ makes the solution unable to gain protons inhibiting the reduction process (Nadagouda et al. [32]; Peterson, [33]. On the other hand, low concentration of hydrogen ions associated with higher $\mathrm{pH}(6)$, enhanced gain of protons resulting in effective reduction process and high yield of iron oxide from the iron chloride.

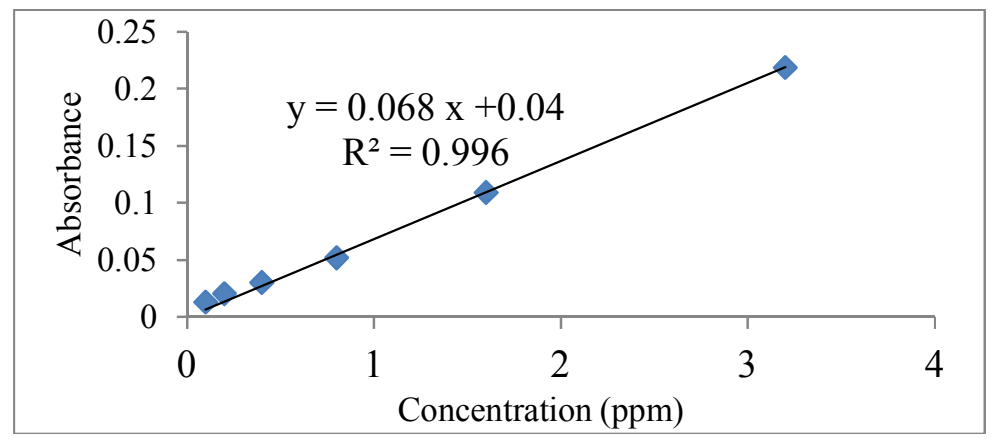

Fig. 1. Linear fit of absorbance of oxide iron oxide nanoparticles versus concentration 
Additionally, the ratio of iron chloride to green tea extract affected the yield of iron oxide. This was due to the fact that, provided the iron chloride substrate is not limiting, then the reducing agent which was green tea in this study has potential for receiving protons, thus the reaction was not inhibited resulting in higher yield of iron oxide [34].

\subsection{Characterisation of Nylon-Ferrous Oxide CHitosan Immobilised Silica Nanocomposites (Nylon-FeOCISNC) Using Uv-vis and XRD}

Development of nylon-ferrous oxide CISNC was confirmed by change in optical density (Uv-vis) of the FeOCISNC gel after nylon nanofibres were placed in the composite gel as indicated in Fig. 2. The difractograms of the nylon-ferrous oxide CISNC were also used to indicate formation of the nanopathogen probe due to change in the difractograms of the original materials as shown in Figs. 3 and 4. The same was observation was made when the composites were observed under a compound microscope indicated in Plate 1.

\subsection{Characterisation of Nanocomposites Using XRF}

Analysis of the individual compounds and nanocomposites indicated notable change in the constituent elements. The ratios of $\mathrm{C}, \mathrm{H}, \mathrm{N}$ and $\mathrm{S}$ changed clearly in the process of forming a complex composite (Table 2).

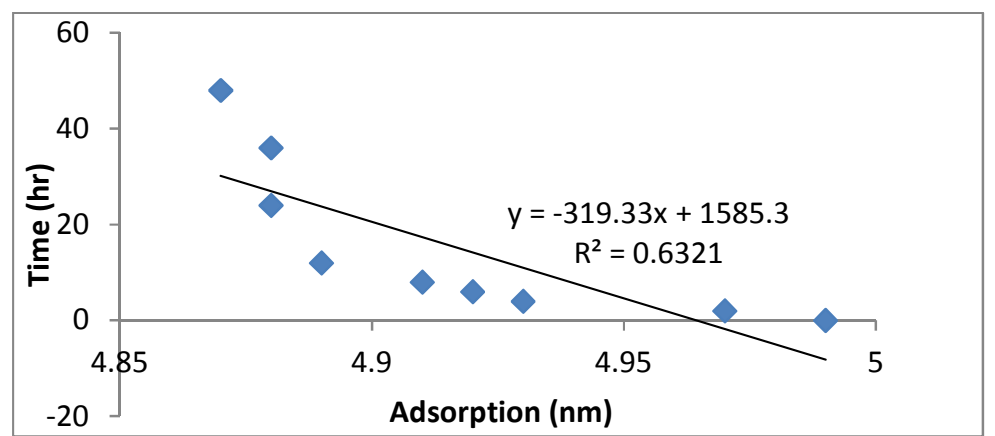

Fig. 2. Change in optical density of ferrous oxide chitosan immobilised silica nanoomposites (FeOCISNC) due to adsorption by nylon nanofibres
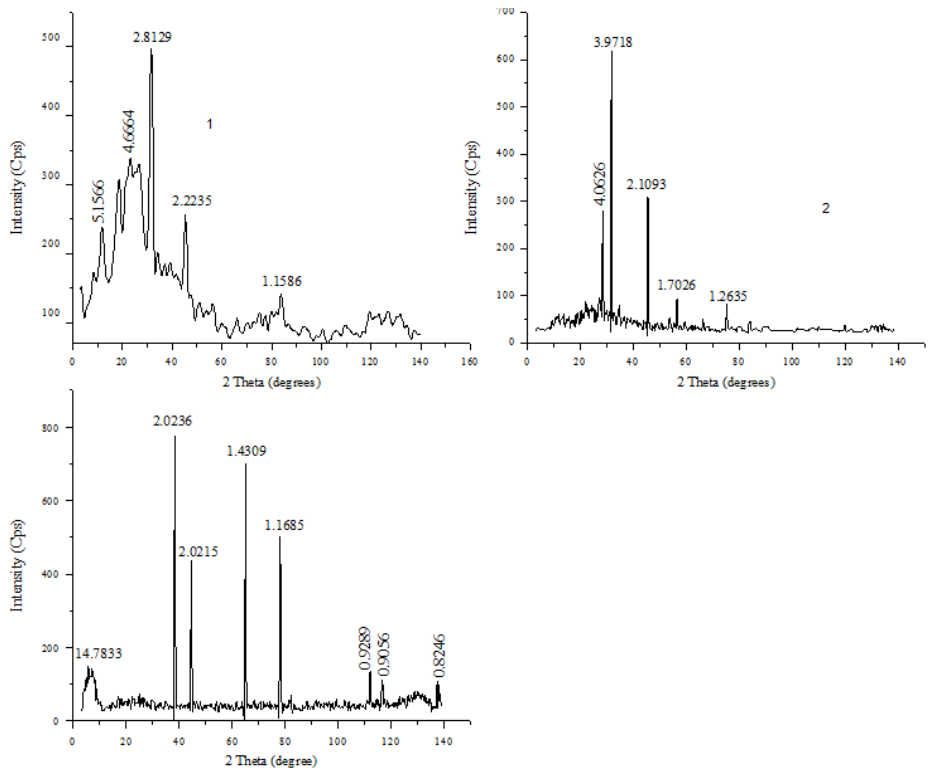

Fig. 3. Difractogram for 1- chitosan immobilised silica nanocomposites (CISNC), 2- Ferrous oxide nanoparticles (FeONPs) and 3- FeOCISNC 


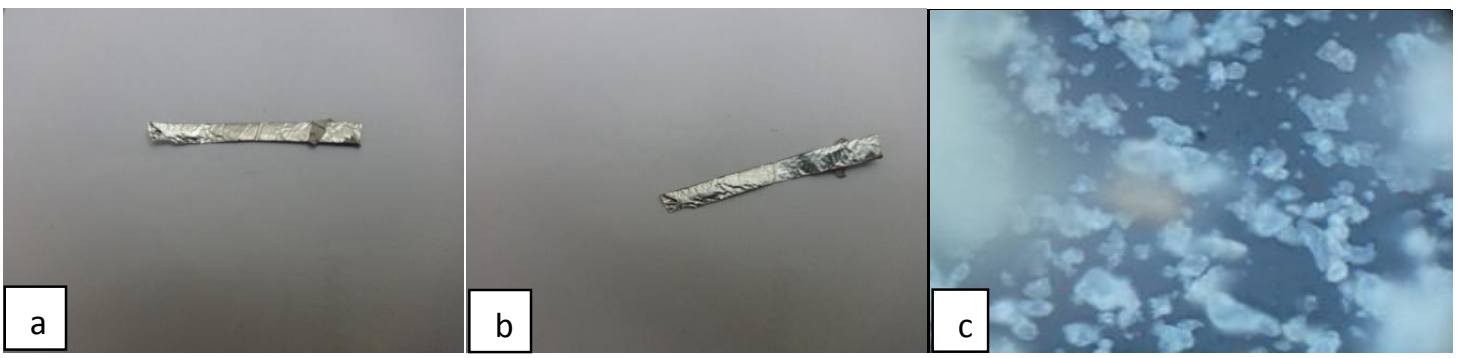

Plate 1. Compound microscope images for nylon nanofibres, nylon-ferrous oxide CISNC and FeOCISNC

a-Nylon nanofibres, b-Nylon-FeOCISNC and c-FeOCISNC

Table 2. Elemental analysis of the nanocomposite probe

\begin{tabular}{|c|c|c|c|c|}
\hline \multirow[t]{2}{*}{ Substance } & \multicolumn{4}{|c|}{$\%$} \\
\hline & C & $\mathrm{H}$ & $\mathbf{N}$ & $\mathbf{S}$ \\
\hline Chitin & 42.35 & 6.627 & 5.80 & 0.153 \\
\hline Chitosan nanoparticles & 34.07 & 6.490 & 4.29 & 0 \\
\hline CISNC & 23.64 & 5.405 & 4.87 & 3.400 \\
\hline FeOCISNC & 23.52 & 4.792 & 4.14 & 1.852 \\
\hline Nylon nanofibres & 12.22 & 1.179 & 2.24 & 0.269 \\
\hline Nylon-FeOCISNC & 29.75 & 6.712 & 6.76 & 1.796 \\
\hline Nylon-FeOCISNC-Rs & 45.31 & 8.404 & 7.41 & 2.536 \\
\hline
\end{tabular}
$\mathrm{XRF}$ is also relatively simple and require less time.

The change in the elemental composition of $\mathrm{C}$, $\mathrm{H}, \mathrm{N}$ and $\mathrm{S}$ was attributed to complexation and formation of composites. For instance, deacetylation and functionalisation of chitosan reduced the $\mathrm{C} / \mathrm{N}$ ratio due to loss of acetyl groups [37]. Complexation of FeONPs with CISNC resulted in displacement of some constituent elements in order to accommodate the compound, while reaction of the Nylonferrous oxide CISNC with the $R$. solanacearum bacteria resulted in increased $\mathrm{C}, \mathrm{H}, \mathrm{N}$ and $\mathrm{S}$ due to integration of organic material into the nanomatrix. Adsorption of bacteria onto the nanocomposite was due to rupturing of bacterial cells that interacted with the ammonia cations in the CISNC by $\mathrm{H}$-bonding, hence demonstrating relatively higher adsorption. In the process, the bacterial cell that possess very high affinity for iron, complexes with the iron oxide nanoparticles in the nylon-ferrous oxide CISNC nanoprobe. This reaction results in increased $\mathrm{C}, \mathrm{H}, \mathrm{N}$ and $\mathrm{S}$ in the composite due to the increased organic matter from the adsorbed bacteria [38].

There was significant $(p=.05)$ reduction in the optical density of $R$. solanacearum when the nanoprobe was placed in the suspension as shown in Table 3. Nylon-ferrous oxide chitosan immobilised silica nanocomposites had the least O.D after adsorption of $R$. solanacearum pathogen, an indication that formation of nanocomposite increased adsorption of the pathogen significantly $(P=.05)$. Adsorption of the pathogen was also depicted by colorimetric visible change in the nanoprobe (Plate 2). In addition, the same findings were corroborated using X-ray diffractograms shown in Fig. 4. However, there was no significant difference in the O.D of $R$. solanacearum and $F$. solani after absorption for $5,30,60 \mathrm{~min}$ by the nanoprobe. In addition, there was no notable colour change when the nanoprobe was placed in the $F$. solani suspension and/or distilled water (Plate 2).

The above study was in agreement with a previous study by Li et al. [39] where, when nylon nanofibers were placed in a gel containing chitosan, silver and nickel, there was a significant decrease in the solution viscosity. Attributed to removal of the elements by nylon nanofibers 
Table 3. Optical densities of $\boldsymbol{R}$. solanacearum suspension after adsorption on the nanoprobe

\begin{tabular}{ll}
\hline Treatment & Change in O.D 600 $\mathrm{nm}$ \\
\hline Chitosan immobilised silica nanocomposites & $0.065 \mathrm{a}$ \\
Nylon nanofibres & $0.069 \mathrm{a}$ \\
Iron oxide nanoparticles (FeONPs) & $0.109 \mathrm{~b}$ \\
Ferrous oxide chitosan immobilised silica nanocomposites (FeOCISNC) & $0.285 \mathrm{c}$ \\
Nylon FeOCISNC 6 hr & $0.307 \mathrm{c}$ \\
Nylon FeOCISNC 8 hr & $0.553 \mathrm{~d}$ \\
Nylon FeOCISNC 48 hr & $0.742 \mathrm{~d}$ \\
Nylon FeOCISNC (F. solani) $6 \mathrm{hr}$ & $0.094 \mathrm{~b}$ \\
Nylon FeOCISNC (F. solani) $8 \mathrm{hr}$ & $0.114 \mathrm{~b}$ \\
Nylon FeOCISNC (F. solani) $48 \mathrm{hr}$ & $0.172 \mathrm{~b}$ \\
\hline
\end{tabular}
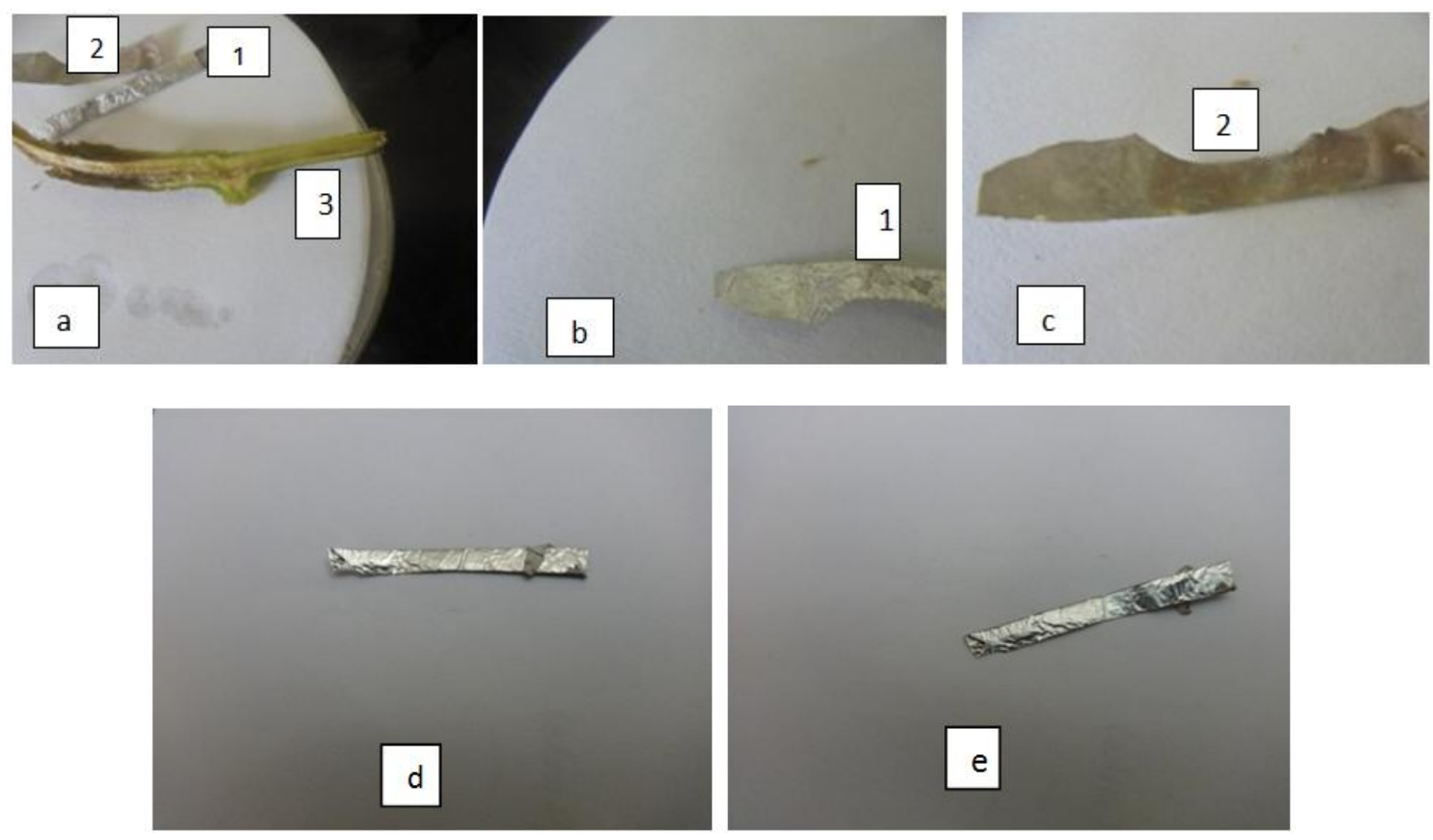

Plate 2. Images of; (a-Nylon-ferrous oxide chitosan immobilised silica nanocomposite colorimetric probe (grey) denoted as 1 (b), and 2 (c) for Nylon-FeOCISNC complexed with $R$. solanacearum (brown), 3 tomato stem colonised by $R$. solanacearum, d-Nylon-FeOCISNC complexed with F. solani (grey) and e-Nylon-FeOCISNC placed in distilled water (grey))

through adsorption. The observation was also corroborated by an increase in the number of ions enhancing conductivity of the nylon nanofibers. Put together, the study validated the observation that nylon nanofibers have good sorption properties particularly for polar particles.

There was notable change in diffractograms after synthesis of nanocomposites. The crystallite sizes of the composites changed after adsorption. The synthesised iron oxide nanoparticles had only two visible peaks which changed to six prominent peaks when the nylon ferrous oxide chitosan immobilised silica nanocomposites were formed. The d-spacing (nm) and full width and half maxima values (FWHM) were also changed after adsorption. Determination of the crystallite sizes was based on the 2-theta $(\theta)$ and FWHM using the Scherrer equation as described by Cullity and Stock, [21] and indicated in Table 4. The major diffraction peak was at 32 (66) and minor peak at 46 (20) conforms to previous studies where iron oxide nanoparticles were synthesised through chemical precipitation method. The diffraction peaks are attributed to the spinel structure of iron oxide [40]. 

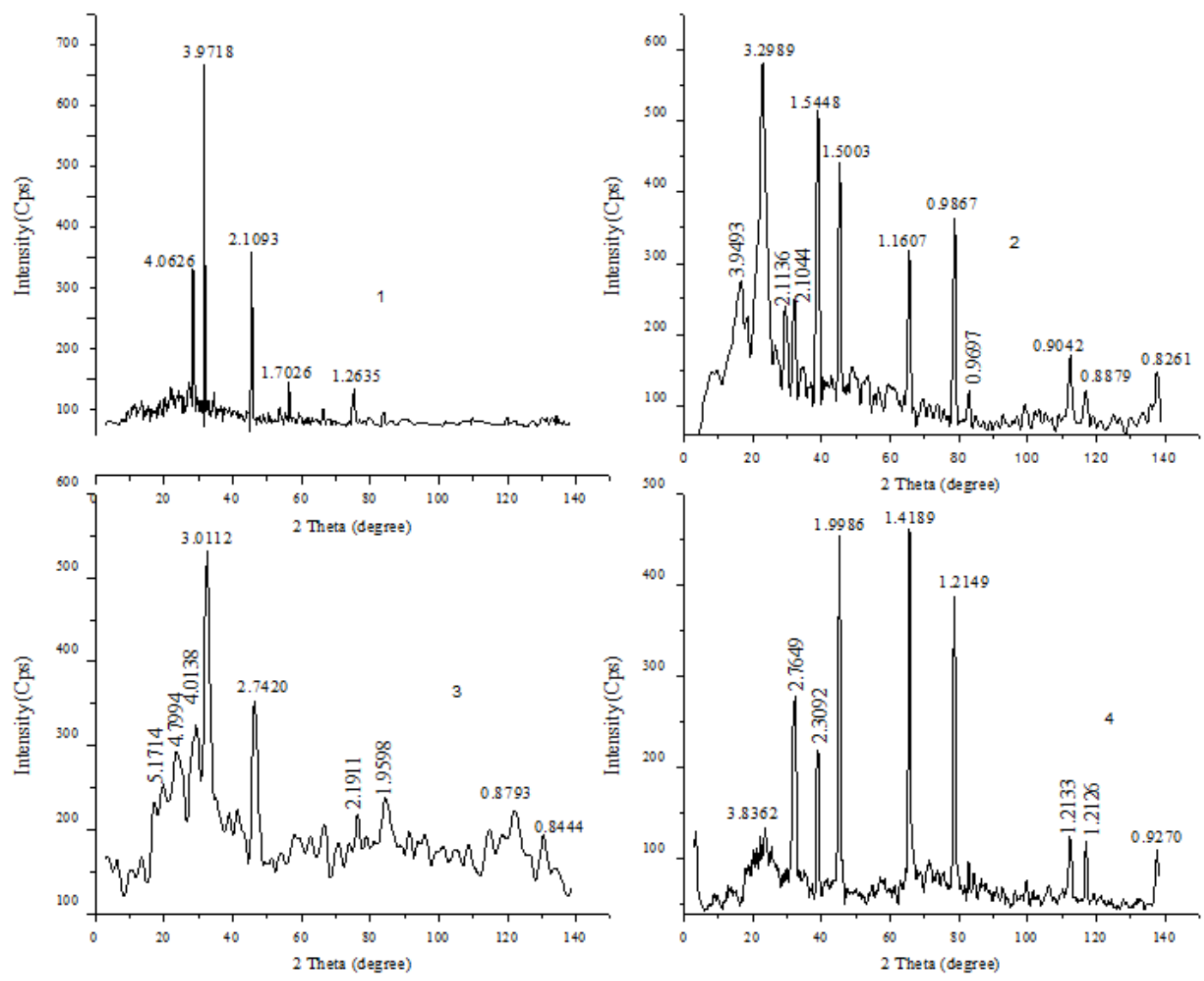

Fig. 4. X-Ray Diffractograms for (1) Nylon nanofibre (2) Ferrous oxide CISNC (3) nylon-ferrous oxide CISNC and (4) Nylon-ferrous oxide CISNC with $R$. solanacearum. The crystallite sizes of nanocomposites varied evidence that there was change in the nanomaterials and that the developed particles were within the nanoscale. The observation is corroborated in Table 4

Table 4. Crystallite sizes of nanocomposites

\begin{tabular}{lllll}
\hline Substance & FWHM & $\boldsymbol{\lambda}(\mathbf{n m})$ & $\mathbf{2 \theta}(\mathbf{d e g})$ & $\begin{array}{l}\text { Crystallite size } \\
\mathbf{( n m )}\end{array}$ \\
\hline CISNC & 0.31 & 1.5418 & 45.47 & 4.80 \\
FeONPs & 0.35 & 1.5418 & 46.26 & 4.30 \\
Nylon nanofibres & 0.13 & 1.5418 & 45.34 & 11.57 \\
FeOCISNC & 0.33 & 1.5418 & 65.58 & 5.00 \\
Nylon-FeOCISNC & 0.33 & 1.5418 & 137.49 & 11.60 \\
Nylon-FeOCISNC- & 0.26 & 1.5418 & 137.56 & 14.75 \\
$R$. solanacearum & & & & \\
\hline
\end{tabular}

R. solanacearum

Key: Iron oxide nanoparticles (FeONPs), Ferrous oxide Chitosan immobilised silica nanocomposites (FeOCISNC), Nylon nanofibres, Nylon-ferrous oxide chitosan immobilised silica nanocomposites (NylonFeOCISNC) and Nylon ferrous oxide chitosan immobilised silica nanocomposites adsorbed with R. solanacearum (Nylon-FeOCISNC-R.s)

Synthesis of ferrous oxide chitosan immobilised silica nanoparticles was paramount in avoiding agglomeration of the synthesised iron oxide nanoparticles. This was necessary to ensure the particles aggregate only in the presence of the analyte. Adsorption of iron nanoparticles on chitosan was possible due to the oxidising effect of chitosan attributed to the amino group charge in chitosan [41]. The iron oxide nanoparticles are embedded on the chitosan-silica gel. The 
embedment is attributed to the binding energy of nitrogen, hydrogen and silicate hydroxide thus formation of chitosan-silica-iron complex [11,37]. This binding also known as chelation is based on mineralisation of magnetite in chitosan hydrogel. According to Budnyak et al. [41], chitosan is considered as an effective chelation and aggregating agent that can enhance formation of a complex. Also the hydroxyl $(-\mathrm{OH})$ group of chitosan interact with the iron oxide ions resulting in a stable and well dispersed colloidal suspension. The coulomb repulsion between the iron nanoparticles played a major role in dispersivity of particles. However, chemical modification of iron oxide nanoparticles with chitosan did not affect the crystal structures since the major peaks at $2 \theta, 39$ (225), 29 (47), 45 (147), 65 (134) and 78 (144) correspond to $8.3840 \AA$ lattice only, though careful analysis indicated physical modifications attributed to the inclusion of chitosan matrix [42].

The choice of nylon nanofibres was informed by the fact that, nylon nanofibers offer good support due to their large surface area and rigidity making it possible to adsorb the nanocomposites. The nylon nanofibres also offer a large surface area for probing the pathogen suspension resulting in colorimetric effect due to reaction of the pathogen and the nanoprobe [43, $44,45]$. Use of nylon-6 electrospun nanofiber mats reinforced with silica and chitosan in this study resulted in a strong nanoprobe due to reinforcement of the ferrous oxide CISNC gel by materials with high tensile strength and toughness, such as the melamine-formaldehyde (MF) resin derived nylon nanofibres [45,46]. The reinforcement altered the morphology and mechanical properties of the composites resulting in better absorption and wetting characteristics. According to Butola et al. [47] and Bhattacharyya and Joshi M [48], immersion of nylon or silk nanofibers in dilute solutions of antimicrobial nanoparticles such as silver, mercury and gold has successfully been done resulting in materials with long term antimicrobial properties. The deposition of the nanoparticles onto the fibers results in significant bacteria reduction for the silk and the nylon fiber.

$R$. solanacearum possess a high affinity for iron particularly in instances of interface $[49,50]$. This is through mechanisms such as; development of siderophores, complexation and chelation. Siderophores are low molecular weight ferric ion specific chelating agents developed by haemaphitic microbial agents used for availing the mineral to the microbial cell. These structures are related to pathogenic virulence and are hydroxamates or catechols. Complexation or chelation of siderophores with iron results in a colorimetric reaction. This formed the basis for formation of the nanoprobe [38]. The colour change was due to the glucosamine units in chitosan rupturing the bacterial cells causing a visually visible chelation of iron oxide ions by the bacterial cells. The colour change in the nylon ferrous oxide chitosan immobilised silica nanocomposites was caused by reduction of iron nanoparticles and formation of a complex with the bacterial cell. Iron is a nutritionally essential trace element playing a major role in metabolic processes of most micro-organisms with bacterial cells having the highest adsorption effect [5,51]. Justifying the current study Sun et al. [52], found out that $R$. solanacearum had the highest absorption capacity for iron compared to other microbes such as B. subtilis, $S$. aureus, $E$. coli and $F$. solani. This was therefore attributed to the colorimetric change observed when the nanoprobe was placed in a suspension of $F$. solani which did not result in a notable colour change, making the nanoprobe an effective tool for differentiating the two pathogens which are characterised by similar symptoms of wilting in infected plants.

Incorporation of chitosan and silica nanoparticles in this study aimed at increasing the effectiveness of the nanoparobe. Chitosan which is a hydrogel material was used due to its excellent biodegradability, biocompatibility, high hydrophilicity attributed to the presence of amino and hydroxyl groups [53,54]. Additionally, silica and iron nanoparticles improved the mechanical and colorimetric properties respectively. The two properties were desirable in formation of the nanoprobe as the strength imbued by silica enhanced ability of the probe to absorb pathogen inoculum until the colour changed. Mesoporous silica nanoparticles used in this study offered a large surface area due to its extensive mesoporosity providing a large surface for harbouring iron oxide and chitosan nanoparticles [55]. Use of silica nanoparticles in enhancing the hyrogel strength had been previously done by Grattner and Teller, [56] resulting in materials with high strength and large adsorbing surfaces. Colour change was attributed to complexation of the bacterial cell with iron oxide $[57,58,59]$. The colour change of the probe in presence of the pathogen justified its usefulness as a diagnostic tool for confirmation of the $R$. solanacearum which is a lethal pathogen of the solanaceae 
family. Also Chassary et al. [60], found out that, nanocomposite fibers that contain nanoscale embedded rigid particles as reinforcements show improved high temperature mechanical property, thermal stability, useful optical, electrical, barrier or other functionality such as improved dyeability, flame retardance and antimicrobial properties. The enhanced properties in composite substances were also corroborated by Zhang et al. [61] in that, the volume and influence of the interfacial interactions increases exponentially with filler materials forming an additional separate phase known as interphase which influences the composite properties to a much greater extent even at low nanofiller loading $(<5 \%)$. Also, adsorption of the ferrous oxide CISNC on nylon nanofibers, aided in changing the compound from wet chemi-sorption which is prone to rapid contamination thus require to be applied under highly sterile conditions compared to the dry chemi-sorption which is easy and ideal under field conditions. The modification also increased the lifespan of the nanocomposite probe. Therefore, the complex nanocomposites have much superior properties compared to conventional one.

From the XRD diffractograms, nylon nanofibre had only two prominent peaks while the resulting composites indicated changes in peaks (Fig. 4). It was noted that nylon ferrous oxide CISNC resulted in more peaks attributed to the physisorption nature of compounds in the nanocomposite. The nylon nanofibers spectra showed characteristic peaks at 2-theta 32.64 and $46.26^{\circ}$ but were shifted to $29.8,39.12,45.32$, $65.58,78.525,112.21$ and $137.49^{\circ}$ in nylon ferrous oxide chitosan immobilised silica nanocomposites suggesting formation of inter and intra-molecular hydrogen bonds in the presence of additional compounds. There was also a significant change in d-spacing of the compounds, the d-spacing increased with adsorption of materials (Figs. 3 and 4). The iron oxide nanoparticles were also characterised by two prominent peaks at 31.7 and $45.47^{\circ}$ attributed to crystallinity of the particles. Adsorption of $R$. solanacearum also altered crystallinity of the nanoprobe. This resulted in slight peak modifications at 29.8, 39.12, 45.32, $65.58,78.52,112.21$ and $137.49^{\circ}$ to 32.27 , $38.98,45.20,65.55,78.63,112.38$ and $137.56^{\circ}$ for the Nylon-FeOCISNC and Nylon-FeOCISNC$R$. solanacearum respectively confirming that complexation may have taken place when the probe had adsorbed the bacterial pathogen [32].

\subsection{Validation of the Colorimetric Nanoprobe Using PCR and Conventional Techniques}

The isolated $R$. solanacearum and $F$. solani used to test the colorimetric nanoprobe were confirmed using morphological and molecular characterisation (Plate 3).

Micro-organisms have unique and distinct morphological and molecular characteristics (Plate 3). The $R$. solanacearum was characterised morphologically by observing the pinkish and whitish coloration after addition of TZC in cultured pathogen. Further, the $F$. solani was confirmed by the presence of chlamodospores under a compound microscope. The morphological characterisation was also ascertained by employing molecular techniques whereby the presence and amplification of DNA confirmed the microbes. The touchdown PCR procedure was preferred since other procedures had limitations in clearly displaying the DNA and PCR ladders. This method ensures that primers avoid amplifying nonspecific sequences. The annealing temperature during a polymerase chain reaction determines the specificity of primer annealing. The melting point of the primer sets the upper limit on annealing temperature where very specific base pairing between the primer and the template occurs because at low temperatures primers bind less specifically resulting in nonspecific sequences. Thus at higher annealing temperatures, there is more specificity and obscurity is eliminated resulting in an accurate detection of the DNA of interest [62]. The DNA of isolated $R$. solanacearum was in the range of $630 \mathrm{bp}$ which is found mainly in the virulent strains $[63,64]$. The virulent strains of $F$. solani occurs around $700 \mathrm{bp}$. However, the procedure unlike the colorimetric nanoprobe was time consuming, labourious and required a high level of precision and expertise which may not be tenable under normal field conditions applicable to an ordinary farmer in sub-Saharan Africa (SSA). The other method of milky exudates was only applicable in heavily infected tomato plants with high bacterial load freely flowing from the cut stem into a beaker containing distilled water [65]. Further, observation of wilting leaves and plants as done by most farmers may not precisely differentiate between wilting caused by bacteria ( $R$. solanacearum) and one caused by fungi $(F$. solani), complicating the disease management [66]. The developed colorimetric 

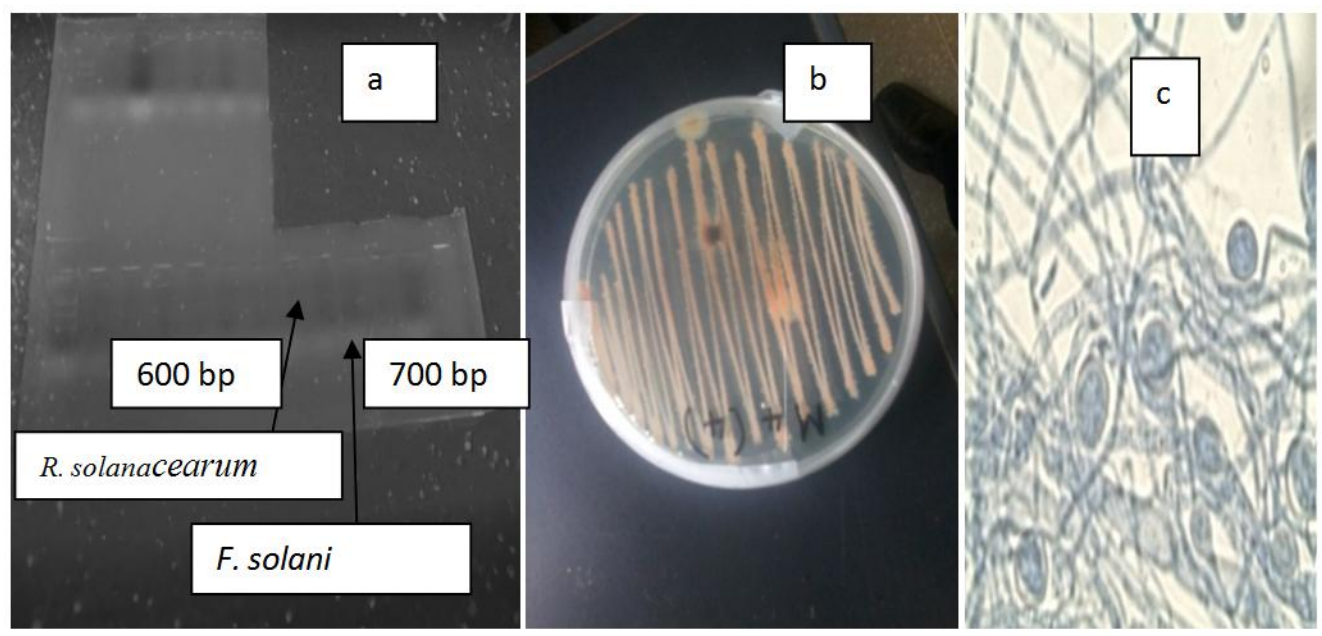

Plate 3. a- Gel image of $R$. solanacearum and $F$. solani (PCR), b- $R$. solanacearum on TZC agar, c- chlamydospores of $F$. solani (x 400)

nylon ferrous oxide chitosan-silica nanocomposite is therefore; user friendly, relatively cheaper and effective in detection of the $R$. solanacearum.

\section{CONCLUSIONS}

Mineralisation of iron oxide nanoparticles in CISNC gel was attributed to ionic chelation while adsorption of ferrous oxide CISNC on nylon nanofibre was due to electrostatic effect. The resultant nylon-ferrous oxide CISNC was regarded as the $R$. solanacearum colorimetric nanoprobe due to the visible colour change observed when the probe was placed in the pathogen suspension. The nanoprobe is simple to use, affordable and effective in the detection of $R$. solanacearum.

\section{ACKNOWLEDGEMENTS}

The authors wish to express their gratitude to Jomo Kenyatta University of Agriculture and Technology, Nairobi, Kenya for funding the research work.

\section{COMPETING INTERESTS}

Authors have declared that no competing interests exist.

\section{REFERENCES}

1. Kenya Horticulture Competitiveness Project (KHCP)-USAID Report; 2012.

2. Kenya Horticulture Development Project (KHDP) Report; 2007.
3. Chilvers M. Molecular diagnostics in plant disease diagnostic clinics. What's the status? Fungal Genome Biol. 2012;2:e102. DOI: $10.4172 / 2165-8056.1000 \mathrm{e} 102$

4. Chaumpluk $P$, Chaiprasart $P$, Vilaivan $T$. Postharvest non-destructive determination of fruits: A model on fruit maturity assay via biosensor based on colorimetric change of gold nanoparticles. Acta Hortic. 2012;945: 205-211.

5. Michailides T, Morgan D, Ma Z, Luo Y, Felts D, Doster M, Reyes H. Conventional and molecular assays aid diagnosis of crop diseases and fungicide resistance. California Agriculture. 2005;59(2):115-123.

6. Kumlachew A. Real-time PCR and its application in plant disease diagnostics. Advances in Life Science and Technology. 2014;27.

Available:www.iiste.org ISSN 2224-7181 (Paper) ISSN 2225-062X (Online)

7. Tim M, Pingsheng J, Ken $P$, Robert $M$, Steve O. Three soilborne tomato diseases caused by Ralstonia and Fusarium species and their field diagnostics. Plant Pathology Department, Florida Cooperative Extension Service, Institute of Food and Agricultural Sciences, University of Florida. 2008;1-6.

8. Nam J, Jang K, Groves J. Detection of proteins using a colorimetric bio-barcode assay. Nat Prot. 2007;2:1438-1444.

9. Agasti S, Rana S, Park M. Nanoparticles for detection and diagnosis. Adv Drug Delivery Rev. 2010;62:316-328. 
10. Artz R, Avery L, Jones D, Killham K. Potential pitfalls in the quantitative molecular detection of Eschrichia coli 0157:H7 in environmental matrices. Canadian Journals of Microbiology. 2006; 52:482-488.

11. Bargossi C, Fiorini M, Montalti M, Prodi L, Zaccheroni N. Coord. Chem. Rev., 2000; 208:17-32.

12. Chi H, Liu BH, Guan G. A simple, reliable and sensitive colorimetric visualisation of melamine in milk by unmodified gold nanoparticles. Analyst. 2010;135: 1070-1075.

13. Melinka A, Mari W, Markus A, Anna J, Hubert K, Reidunn B, Aalen A, Georg F. Tools and strategies to match peptideLigand Receptor Pairs; 2014.

14. Yang $\mathrm{R}, \mathrm{He} J, \mathrm{Xu} \mathrm{L}, \mathrm{Yu}$ J. Polymer. 2009;50:5846-5850.

15. Shahwan T, Abu Sirriah S, Nairat M, Boyali E, Eroglu A, Scoh T, Hallam K. Green synthesis of iron nanoparticles and their application as a fenton-like catalyst for the degradation of aqueous cationic and anionic dyes. J. Chem. Engin. 2011;172: 258-266.

16. Blank AB, Eksperiandova LP. Specimen preparation in X-ray fluorescence analysis of materials and natural objects. WileyInterscience (Abstract); 1997.

17. Shrifian-Esfahni A, Salehi M, Nasr-Esfahni M, Ekramian E. Chitosan- modified superparamagnetic iron oxide nanoparticles: Design, fabrication, characterisation and antibacterial activity. Chemik. 2015;69(1): 19-32.

18. Mafuma T. Immobilisation of electric eel acetylcholinesterase on nanofibres electrospun from a nylon and chitosan blend. Master of Science thesis, Rhodes University; 2013.

19. Jolanta K, Malgorzata C, Zbignew K, Anna B, Krysztof B, Jorg T, Piotr S. Application of spectroscopic methods for structural analysis of chitin and chitosan. J. Marine Drugs. 2010;8:1570-1577.

20. French E, Gutarra I, Aley P, Elphinstone J. Culture media for $R$. solanacearum isolation, identification and maintenance. Fitopatologia. 1995;30(3):26-130.

21. Cullity B, Stock S. Elements of X-ray diffraction, $3^{\text {rd }}$ Ed., Prentice-Hall Inc. 2001; 167-171.

22. Gulcin I. Antioxidant activity of caffeic acid (3, 4-dihydroxycinnamic acid). Toxicology J. 2006;217:213-220.
23. Ling $\mathrm{R}$, Khizar $\mathrm{H}$, Yi L, Eric $\mathrm{K}$, Shuqin $\mathrm{X}$, Chengsheng J, Fang Z, Xiaoming Z. Effect of ultrafiltration and fining adsorbents on the clarification of green tea. J. Food Engineering. 2011;102:321-326.

24. Pereira D, Valentao P, Pereira J, Andrade P. Phenolics: From chemistry to biology. Molecules J. 2009;14:2202-2211.

25. Sun $Y$, Li X, Cao X. A method for the preparation of stable dispersion of zero valent iron nanoparticles. Colloids Surf. A. 2007;308:60-66.

26. Prasad K, Yang B, Dong $X$, Jiang G, Zhang $\mathrm{H}$, Xie $\mathrm{H}$, Jiang $\mathrm{Y}$. Flavonoid contents and antioxidant activities from Cinnamomum species. Innov. Food Sci. Emerg. Technol. 2009;10:627-632.

27. Wang $\mathrm{H}$, Helliwell $\mathrm{K}$. Determination of flavanols in green tea and black tea leaves and green tea infusions by high performance liquid chromatography. Food Reserves International. 2001;34:223-227.

28. Karori S, Wachira F, Wanyoko J, Ngure R. Antioxidant capacity of different types of tea products. African Journal of Biotechnology. 2007;6:2287-2296.

29. Carmen C, Artacho R, Gime'nez R. Beneficial effects of green tea-a review. Journal of the American College of Nutrition. 2006;25:79-99.

30. Koech K, Wachira F, Ngure R, Wanyoko J, Bii C, Karori S, Kerio L. Antioxidant, antimicrobial and synergistic activities of tea polyphenols. African Crop Science Journal. 2001;22(4):837-846.

31. Dutta A, Mahapatra S, Datta J. Int. J. Hydrogen Energy. 2011;36:14898-14906.

32. Nadagouda M, Castle A, Murdock R, Hussain S, Varma R. In vitro biocompatibility of nanoscale zerovalent iron particles (NZVI) synthesised using tea polyphenols. Green Chem. 2010;12: 114-122.

33. Peterson J, Dwyer J, Bhagwat $S$, Haytowitz D, Holden J, Eldridge A, Beecher G, Aladesanmi J. Major flavonoids in dry tea. J. Food Composition and Analysis. 2005;18(6):487-501.

34. Leung L, Yakun S, Chen R, Zhang Z, Hang $Y$, Chen Z. Theaflavins in black tea and catechins in green tea are equally effective in antioxidant activity. Journal of Nutrition. 2001;131:2248-2251.

35. Al-Eshaikh MA, Kadachi A. Toxic heavy metal analysis in residential paint using $X$ - 
ray fluorescence (XRF) technique. In: Proceedings of the $12^{\text {th }}$ International Conference on Machine Design and Protection, September 5-8, 2006, Kusadast, Turkey.

36. Ida H, Segawa T, Tohyama S, Kawai J. Analysis of painted steel by hand-held $X$ ray fluorescence spectrometer. Kyoto University, Skyo-Ku, 606-8501 Japan; 2005.

37. Qian Y, Goodell B, Felix C. The effect of low molecular weight chelators on iron chelation and free radical generation as studied by ESR measurement. Chemosphere. 2002;48:21-28.

38. Lawton L, Cornish B, MacDonald A. Removal of cyanobacterial toxins (microcystins) and cyanobacterial cells from drinking water using domestic water filters. Water Research. 1998;32(3): 633-638.

39. Li L, Bellan L, Craighead H, Frey W. Formation and properties of nylon- 6 and nylon-6/ montmorillonite composite nanofibers by electrospinning. Polymer. 2006;47:6208-6217.

40. Jiang $W$, Yang $K$, Vachet $R$, Xing $B$. Interaction between oxide nanoparticles and biomolecules of the bacterial cell envelop as examined under Infrared Spectroscopy. Langmuir. 2010;26: 18071-18077.

41. Budnyak M, Tetykh A, Yanovska S. Chitosan and its derivatives as sorbents for effective removal of metal ions. Surface. 2013;5(Suppl 20):118-34.

42. Goycoolea F, Higuera-Ciapara I, Alonso M. Chitosan- polysaccharide blended nanoparticles for controlled drug delivery. in Handbook of Natural-based Polymers for Biomedical Applications, R. L. Reis, N.M. Neves, J. F. Mano, M. E. Gomes, A. P. Marques, and H. S. Azevedo, Eds. 2008;644-679.

43. Agasti S, Rana S, Park M. Nanoparticles for detection and diagnosis. Adv Drug Delivery Rev. 2010;62:316-328.

44. Safavi A, Abdollahi H. Speciation of Fe (II) and $\mathrm{Fe}$ (III) with chromagenic mixed reagents by principal- component regression. Microchem. J. 1999;63: 211-217.

45. Wan W, Ngah S, Ghani A, Kamari A. Adsorption behaviour of $\mathrm{Fe}$ (II) and $\mathrm{Fe}$ (III) ions in aqueous solution on chitosan and cross-linked chitosan beads. Bioresour. Technol. 2005;96:443-450.
46. Yang Z, Zhuang L, Tan G. Preparation and adsorption behavior for metal of chitosan cross-linked by dihydroxyazacrown ether. J. Appl. Polym. Sci. 2002;85:530-535.

47. Butola B, Joshi M, Kumar S. Hybrid organicinorganic POSS (polyhedral oligomeric silsesquioxane)/polypropylene nanocomposite filaments. Fibers and Polymers. 2010;11(3):1137-1145.

48. Bhattacharyya, Joshi M. Functional properties of microwave absorbent nanocomposite coatings based on thermoplastic polyurethane-based and hybrid carbon-based nanofillers. Polymers for Advanced Technologies. 2012;23(6): 975-983.

49. Auffan M, Achouak W, Rose J, Roncato M, Chane'ac C, Waite D, Masion A, Woicik J, Wiesner R, Bottero J. Relation between the redox state of iron-based nanoparticles and their cytotoxicity toward Escherichia coli. Environ. Sci. Technol. 2008;42:6730-6735.

50. Miethke M, Marahiel M. Siderophorebased iron acquisition and pathogen control. Microbiol. Mol. Biol. Rev. 2007; 71413-451.

51. Amemiya Y, Arakaki A, Staniland S, Tanaka T, Matsunaga T. Controlled formation of magnetite crystal by partial oxidation of ferrous hydroxide in the presence of recombinant magnetotactic bacterial protein Mms6. Biomaterials. 2007;28(35):5381-5389.

52. Sun H, Lu X, Gao P. The exploration of the antebacterial mechanism of $\mathrm{Fe} 3+$ against bacteria. Brazilian J. of Microl. 2010;42: 410-414.

53. Lifeng $Q$, Zirong $X$, Xia J, Caihong $H$, Xiangfei Z. Preparation and antibacterial activity of chitosan nanoparticles. J. Carbohydrate Research. 2004;339: 2693-2700.

54. Hutchison J. Greener nanoscience: A proactive approach to advancing applications and reducing implications of nanotechnology. ACS Nano. 2008;2(3): 395-402.

55. Joshi $M$, Biswas $D$, Sarvanan A, Mukhopadhyay R. Nylon 6/ Nanoclay filaments and their cords. Journal of Applied Polymer Science. 2012;125: 224-234.

56. Grattner C, Teller J. New types of silicafortified magnetic nanoparticles as tools for 
molecular biology applications. Journal of Magnetism and Magnetic Materials. 1999; 194(1-3):8-15.

57. Sun $Y$, Liu $Y, Q u$ W. Combining nanosurface chemistry and microfluidics for molecular analysis and cell biology. Anal Chim Acta. 2009;650:98-105.

58. Rosi N, Mirkin C. Nanostructures in biodiagnostics. Chem Rev. 2005;105: 1547-1562.

59. Sun $H$, Zhang $W$, Lu $X$, Gao $P$. Siderophore production from 27 filamentous fungal strains and a novel siderophore with potential biocontrol applications from Aspergillus niger An76. J. Life. Sci. 2008;2(1):19-26.

60. Chassary P, Vincent T, Guibal E. Metal anion sorption on chitosan and derivative materials: A strategy for polymer modification and optimum use. React Funct Polym. 2004;60:137-49.

61. Zhang X, Guo Q, Cui D. Recent advances in nanotechnology applied to biosensors. Sensors. 2009;1033-1053.

62. Hecker K, Roux K. High and low annealing temperatures increase both specificity and yield in touchdown and step down PCR. Biotechniques. 1996;20(3):478-85.

63. Alka G, Abhinav G, Chakrabarti S, Wamik A, Durai S, Khurana S. Identification of $R$. solanacearum using conserved genomic regions. International Journal for Biotechnology and Molecular Biology Research. 2011;2(1):23-30.

64. Fujiwara A, Kawasaki T, Usami S, Fujie M, Yamada T. Genomic characterization of $R$. solanacearum phage $\Phi$ RSA1 and its related prophage ( $\Phi R S X)$ in Strain GMI10007. Journal of Bacteriology. 2008; 190(1):143-156.

65. Kim S, Olson T, Schaad N, Moorman G. $R$. solanacearum race 3 , biovar 2 , the causal agent of brown rot of potato, identified in geraniums in Pennsylvania, Delaware, and Connecticut. Plant Disease. 2003;87:450.

66. Jahanshir A, Dzhalilov S. The effects of fungicides on $F$. oxysporum $F$. Sp. lycopersici associated with fusarium wilt of tomato. Journal of Plant Protection Res. 2010;50(2). 


\section{APPENDIX}

\section{ANOVA for iron nanoparticles (FeONPs) yield}

Variate: FeONPs_conc

\begin{tabular}{llllll}
\hline Source of var. & df & ss & ms & v.r & F pr. \\
\hline Rep stratum & 2 & 0.07401 & 0.03701 & 1.46 & $<0.001$ \\
Treat & 14 & 160.33089 & 11.45221 & 452.08 & \\
Residual & 28 & 0.70931 & 0.02533 & 1.46 & \\
Total & 44 & 161.11421 & 0.03701 & 452.08 & \\
\hline
\end{tabular}

2. ANOVA for $R$. solanacearum optical densities after adsorption on to the nanoprobe

Variate: O_D_2_000

\begin{tabular}{llllll}
\hline Source of var. & df & ss & ms & v.r & F pr. \\
\hline Rep stratum & 2 & 0.018093 & 0.009046 & 1.09 & $<0.001$ \\
Treat & 6 & 2.454660 & 0.409110 & 49.27 & \\
Residual & 12 & 0.099645 & 0.008304 & & \\
Total & 20 & 2.572398 & & & \\
\hline
\end{tabular}

3. Characterisation of nanocomposites using X-ray powder diffractometer

I. Chitosan Immobilised Silica Nanocomposites (CISNC)

\begin{tabular}{llllllll}
\hline No. & 2-theta(deg) & d (ang.) & Height(cps) & FWHM(deg) & $\begin{array}{l}\text { Int. I(cps } \\
\text { deg) }\end{array}$ & Int. W(deg) & $\begin{array}{l}\text { Asym. } \\
\text { factor }\end{array}$ \\
\hline 1 & $31.7(2)$ & $2.82(2)$ & $41(18)$ & $4.8(6)$ & $420(24)$ & $10(5)$ & $5(2)$ \\
2 & $45.47(8)$ & $1.993(3)$ & $80(26)$ & $0.31(12)$ & $43(4)$ & $0.5(2)$ & $2(3)$ \\
\hline
\end{tabular}

II. Nylon nanofibres

\begin{tabular}{llllllll}
\hline No. & $\begin{array}{l}\text { 2- } \\
\text { theta(deg) }\end{array}$ & d(ang.) & Height(cps) & FWHM(deg) & $\begin{array}{l}\text { Int. I(cps } \\
\text { deg) }\end{array}$ & Int. W(deg) & $\begin{array}{l}\text { Asym. } \\
\text { factor }\end{array}$ \\
\hline 1 & $32.64(6)$ & $2.742(5)$ & $66(24)$ & $0.41(5)$ & $30(4)$ & $0.4(2)$ & $1.3(8)$ \\
2 & $46.26(10)$ & $1.961(4)$ & $47(20)$ & $0.35(9)$ & $20(3)$ & $0.4(2)$ & $1.3(16)$ \\
\hline
\end{tabular}

\begin{tabular}{llllllll}
\hline No. & 2-theta(deg) & d(ang.) & Height(cps) & FWHM(deg) & $\begin{array}{l}\text { Int. I(cps } \\
\text { deg) }\end{array}$ & Int. W(deg) & $\begin{array}{l}\text { Asym. } \\
\text { factor }\end{array}$ \\
\hline 1 & $28.420(16)$ & $3.1379(17)$ & $202(41)$ & $0.18(3)$ & $42(4)$ & $0.21(6)$ & $2.5(11)$ \\
2 & $31.622(11)$ & $2.8271(10)$ & $785(81)$ & $0.128(14)$ & $145(5)$ & $0.18(3)$ & $2.1(9)$ \\
3 & $45.340(15)$ & $1.9985(6)$ & $362(55)$ & $0.13(2)$ & $81(4)$ & $0.22(4)$ & $1.0(6)$ \\
\hline
\end{tabular}

III. Nylon Ferrous oxide Chitosan Immobilised Silica Nanocomposites (NyFeOCISNC)

\begin{tabular}{llllllll}
\hline No. & 2-theta(deg) & d(ang.) & $\begin{array}{l}\text { Height } \\
\text { (cps) }\end{array}$ & FWHM(deg) & $\begin{array}{l}\text { Int. I } \\
\text { (cps deg) }\end{array}$ & Int. W(deg) & $\begin{array}{l}\text { Asym. } \\
\text { factor }\end{array}$ \\
\hline 1 & $29.83(7)$ & $2.992(7)$ & $47(18)$ & $0.49(16)$ & $46(6)$ & $1.0(5)$ & $5(4)$ \\
2 & $39.12(4)$ & $2.301(2)$ & $225(39)$ & $0.33(3)$ & $97(5)$ & $0.43(10)$ & $4(3)$ \\
3 & $45.322(13)$ & $1.9993(5)$ & $147(31)$ & $0.38(4)$ & $73(4)$ & $0.49(14)$ & $4(3)$ \\
4 & $65.58(3)$ & $1.4223(6)$ & $134(30)$ & $0.33(3)$ & $53(4)$ & $0.39(12)$ & $3.0(11)$ \\
5 & $78.525(12)$ & $1.21711(16)$ & $144(31)$ & $0.37(3)$ & $60(4)$ & $0.42(12)$ & $0.5(2)$ \\
6 & $112.21(6)$ & $0.9280(3)$ & $56(19)$ & $0.28(6)$ & $19(3)$ & $0.34(17)$ & $0.5(6)$ \\
7 & $137.49(4)$ & $0.82650(12)$ & $51(18)$ & $0.33(6)$ & $24(3)$ & $0.5(2)$ & $0.5(3)$ \\
\hline
\end{tabular}


IV. NFeCISNC- $R$. solanacearum

\begin{tabular}{llllllll}
\hline No. & $\begin{array}{l}\text { 2- } \\
\text { theta(deg) }\end{array}$ & d(ang.) & Height(cps) & FWHM(deg) Int. I(cps & Int. W(deg) & $\begin{array}{l}\text { Asym. } \\
\text { factor }\end{array}$ \\
\hline 1 & $32.27(4)$ & $2.772(4)$ & $123(29)$ & $0.36(3)$ & $47(4)$ & $0.38(12)$ & $2.6(14)$ \\
2 & $38.92(2)$ & $2.3124(13)$ & $165(33)$ & $0.22(3)$ & $49(4)$ & $0.30(8)$ & $0.4(3)$ \\
3 & $45.20(3)$ & $2.0042(12)$ & $334(47)$ & $0.19(5)$ & $97(6)$ & $0.29(6)$ & $0.7(6)$ \\
4 & $65.55(2)$ & $1.4229(5)$ & $351(48)$ & $0.24(3)$ & $110(5)$ & $0.31(6)$ & $1.2(5)$ \\
5 & $78.635(19)$ & $1.2157(2)$ & $269(42)$ & $0.24(2)$ & $72(4)$ & $0.27(6)$ & $0.7(2)$ \\
6 & $112.38(4)$ & $0.9271(2)$ & $92(25)$ & $0.20(4)$ & $27(3)$ & $0.29(11)$ & $2(3)$ \\
7 & $137.56(2)$ & $0.82632(7)$ & $99(26)$ & $0.26(4)$ & $40(4)$ & $0.41(14)$ & $0.53(19)$ \\
\hline
\end{tabular}

(c) 2016 Maina et al.; This is an Open Access article distributed under the terms of the Creative Commons Attribution License (http://creativecommons.org/licenses/by/4.0), which permits unrestricted use, distribution, and reproduction in any medium, provided the original work is properly cited.

Peer-review history:

The peer review history for this paper can be accessed here: http://sciencedomain.org/review-history/14238 